\title{
Asthma Control and Its Relationship with Obstructive Sleep Apnea (OSA) in Older Adults
}

\author{
Mihaela Teodorescu, ${ }^{1,2,3}$ David A. Polomis, ${ }^{2}$ Ronald E. Gangnon, ${ }^{4}$ Jessica E. Fedie, ${ }^{1,2}$ \\ Flavia B. Consens, ${ }^{5}$ Ronald D. Chervin, ${ }^{5}$ and Mihai C. Teodorescu ${ }^{1,3,6}$
}

${ }^{1}$ James B. Skatrud Pulmonary/Sleep Research Laboratory, Medical Service, William S. Middleton Memorial Veterans Hospital, Madison, WI, USA

${ }^{2}$ Section of Allergy, Pulmonary and Critical Care Medicine, USA

${ }^{3}$ Center for Sleep Medicine and Sleep Research/Wisconsin Sleep, University of Wisconsin School of Medicine and Public Health, Madison, WI, USA

${ }^{4}$ Department of Biostatistics and Medical Informatics and Population Health Sciences, University of Wisconsin School of Medicine and Public Health, Madison, WI, USA

${ }^{5}$ Department of Neurology and Sleep Disorders Center, University of Michigan Health System, Ann Arbor, MI, USA

${ }^{6}$ Section of Geriatrics and Gerontology, University of Wisconsin School of Medicine and Public Health, Madison, WI, USA

Correspondence should be addressed to Mihai C. Teodorescu; mct@medicine.wisc.edu

Received 29 May 2013; Revised 12 September 2013; Accepted 13 September 2013

Academic Editor: Giora Pillar

Copyright ( $(2013$ Mihaela Teodorescu et al. This is an open access article distributed under the Creative Commons Attribution License, which permits unrestricted use, distribution, and reproduction in any medium, provided the original work is properly cited.

\begin{abstract}
Background/Objectives. Asthma in older individuals is poorly understood. We aimed to characterize the older asthma phenotype and test its association with obstructive sleep apnea (OSA). Design. Cross-sectional. Setting. Pulmonary and Asthma/Allergy clinics. Participants. 659 asthma subjects aged 18-59 years (younger) and 154 aged 60-75 (older). Measurements. Sleep Apnea scale of Sleep Disorders Questionnaire (SA-SDQ), asthma severity step (1-4, severe if step 3 or 4), established OSA diagnosis, continuous positive airway pressure (CPAP) use, and comorbidities. Results. Older versus younger had worse control, as assessed by asthma step, lung function, and inhaled corticosteroid use. Among older subjects, after controlling for known asthma aggravators, OSA diagnosis was the only factor robustly associated with severe asthma: on average, OSA was associated with nearly 7 times greater likelihood of severe asthma in an older individual $(\mathrm{OR}=6.67)$. This relationship was of greater magnitude than in younger subjects $(\mathrm{OR}=2.16)$. CPAP use attenuated the likelihood of severe asthma in older subjects by $91 \%(P=0.005)$, much more than in the younger asthmatics. Conclusion. Diagnosed OSA increases the risk for worse asthma control in older patients, while CPAP therapy may have greater impact on asthma outcomes. Unrecognized OSA may be a reason for poor asthma control, particularly among older patients.
\end{abstract}

\section{Introduction}

Asthma is a major health problem in the general population. As many patients develop asthma in childhood or adolescence, large community studies have focused on asthma in early years. While the prevalence is estimated to be $6.5-17 \%$ [1] and may be similar to that seen in younger adults, asthma is frequently underrecognized as a geriatric respiratory disorder and often remains undiagnosed [2]. This may be due to the fact that older adults tend to underreport symptoms, have limited subjective awareness, lack perception or attribution to pulmonary pathology [2], or lack access to lung function testing such as spirometry and peak flow [3].

Asthma-associated morbidity and mortality increase with older age [4]. The number of unscheduled ambulatory visits, emergency visits, and hospitalizations is high in elderly asthmatics [5]. Elderly individuals with asthma in comparison to young adults have 14 -fold higher asthma-related death rates and are twice as likely to be hospitalized in a given year [6]. Death rates attributable to asthma increase exponentially 
after age of 65 [7], with women and particularly black women being the most affected [8]. Nonetheless, suboptimal therapeutic management has often been the norm [4], perhaps as a result of the poor recognition and understanding of this phenotype. Inhaled corticosteroids were historically underutilized, with deviation from recommended clinical guidelines. In addition, therapeutic decisions may have been hampered by the fact that many randomized treatment trials excluded patients older than 65 years, or those with substantial comorbidity [9].

Quality of sleep in older patients with asthma is poorer compared to those with chronic obstructive pulmonary disease (COPD) or chronic bronchitis [10]. Whereas some comorbid conditions, such as rhinitis and gastroesophageal reflux disease (GERD), are well recognized to aggravate asthma, little is known about the potential role of obstructive sleep apnea (OSA), another condition with high prevalence in the elderly [11]. Accumulating data in younger samples suggests a role of OSA in asthma control. Treatment of OSA with continuous positive airway pressure (CPAP) improves asthma symptoms, peak flow rates, and quality of life $[12,13]$. The sleep disorder is also an important risk factor for frequent exacerbations in difficult-to-control asthma patients [14].

We therefore used data from a sizeable, ongoing survey [15] to examine whether clinically-diagnosed and untreated OSA predicts asthma control among older patients and to assess whether the magnitude of such associations resembles those found among younger patients. Our hypothesis was that OSA predicts worse asthma control in older patients, as it does in the young. Preliminary results of this work have been published in abstract form [16]. Subsets of these data have been analyzed on other aspects of the relationships between OSA and asthma, which were included in our prior reports [15-17].

\section{Methods}

2.1. Study Participants. The sample included asthma patients returning for routine follow-up visits at the University of Michigan Pulmonary Clinics and Asthma-Airways Center and at the University of Wisconsin Allergy and Pulmonary Clinics. Subjects were enrolled as part of a larger ongoing study on the relationship between OSA and asthma, including use of informed consent and approval from each Institutional Review Board. Data were collected between May 2004 and April 2006 (at the University of Michigan) and July 2007 and December 2009 (at the University of Wisconsin). As required by the design of the parent study, patients 18-75 years old who were able and willing to provide informed consent and complete our survey were invited to participate. All subjects had specialist-diagnosed and managed asthma [18]. Patients underwent history, physical examination, asthma control assessments, and spirometry with each clinic visit. Those at urgent asthma-related visits or pregnant women were not enrolled.

2.2. Survey Content. The self-administered survey package, distributed by study assistants, is comprised of two questionnaires and additional questions on demographics. The first instrument, the Sleep Apnea scale of the Sleep Disorders Questionnaire (SA-SDQ) assesses OSA symptoms and summarizes its risk [19]. This scale consists of eight symptom items inquiring about loud snoring disruptive to the bed partner, cessation of breathing in sleep, sudden gasping arousals, worsening of snoring while supine or after alcohol, nocturnal sweating and nasal congestion, and history of hypertension. Responses are recorded on a 5-point Likert scale ("never" to "always"). Demographic data on weight, age, smoking, and body mass index (BMI) are rated on a 1 to 5 scale, with the overall SA-SDQ score ranging between 12 and 60 . This scale was validated in a large sample of sleep patients [19].

The second survey instrument asked about frequency of daytime and nighttime asthma symptoms (as below) following the National Asthma Education and Prevention Program classification of asthma severity based on clinical features [20], as we previously reported [15]; two additional items asked about duration of asthma symptoms and physicianestablished diagnosis.

2.3. Medical Records Review. Reviews were conducted by study physicians to extract information on established diagnoses of lung disease (such as allergic bronchopulmonary aspergillosis, chronic obstructive pulmonary disease, and interstitial lung diseases), on OSA diagnosis (which had been established by clinical polysomnography (PSG)), and whether or not CPAP was being used as documented in the clinic visit notes at the time of the survey. PSG indices or objective CPAP use were not collected in this study. Also, information was extracted on other comorbidities (e.g., GERD, rhinitis, chronic sinusitis, nasal polyps, and psychiatric diseases such as depression, anxiety, panic, or bipolar disorders) and current asthma medications, and from spirometry to help assess asthma step.

The asthma step was assigned, according to NAEPP guidelines [20], as we previously reported [15], in order of increasing severity: (i) step 1 (mild-intermittent asthma), patients with daytime symptoms $\leq 2$ days/week, nighttime symptoms $\leq 2$ nights/month, Forced Expiratory Volume in first second $\left(\mathrm{FEV}_{1}\right) \geq 80 \%$ predicted and peak expiratory flow rates (PEFR) variability $<20 \%$; (ii) step 2 (mildpersistent asthma), patients with daytime symptoms 3-6 days/week, nighttime symptoms more than 2 nights/month (3-4 nights/month), $\mathrm{FEV}_{1} \geq 80 \%$ and PEFR variability 20 $30 \%$; (iii) step 3 (moderate-persistent asthma), patients with daily asthma symptoms, nocturnal symptoms $\geq 5$ /month (or $>$ once/week), $\mathrm{FEV}_{1}$ between $>60 \%-<80 \%$ or PEFR variability $>30 \%$; (iv) step 4 (severe-persistent asthma), patients with continuous daytime symptoms, frequent nighttime symptoms, $\mathrm{FEV}_{1} \leq 60 \%$ or PEFR variability $>30 \%$. The PEFR variability was calculated by dividing the difference between the highest and the lowest daily PEF value by the daily mean PEF and multiplying the result by 100 [21]. Attempts were made to obtain current peak flow diaries from patients or their medical records; due to their limited availability, for uniformity, the peak flow variability could not be used in 
asthma step assessment. The asthma step was determined by the most severe remaining qualifying features.

2.4. Data Analysis. Subjects were categorized into an older (60-75 years) or younger group (18-59 years). Baseline characteristics were summarized as mean \pm standard deviation (SD) for continuous variables and percentages for categorical variables. The BMI was stratified per CDC criteria $(<25,25-$ 29.9 and $\geq 30 \mathrm{~kg} / \mathrm{m}^{2}$ ) and used as an ordinal variable. Occurrence of OSA symptoms "usually" or "always" (responses of 4 or 5 on the SA-SDQ) defined "habitual" symptoms. The validated cutoffs of SA-SDQ $\geq 36$ for men and $\geq 32$ for women defined high OSA risk [19]. Age at asthma onset was computed based on current age and duration of asthma symptoms, and age at physician-established diagnosis was recorded. Asthma step 3 or 4 defined severe asthma. To assess for any differential expression of relationships between daytime or nighttime asthma symptoms with OSA, daytime asthma symptoms occurring $>2$ days/week defined persistent daytime symptoms, and nighttime symptoms occurring $>2$ nights/month defined persistent nighttime symptoms.

The initial analysis was conducted on data from subjects without OSA and those with diagnosed OSA but not on CPAP treatment at the time of survey. Two-sample $t$-test, chi-squared, or Fisher exact test were used, as appropriate, to test for group differences in baseline variables. Ordinal logistic or logistic regression were used to test for univariate relationships of asthma step or severe asthma as the dependent variables with OSA diagnosis, BMI and traditional contributors to asthma control (demographics [age, gender and African-American race], rhinitis, chronic sinusitis, nasal polyps, GERD, and psychiatric disease) [14, 22]. The same techniques were employed to fit multivariate models with asthma step, severe asthma or persistent asthma symptoms as the outcomes, and OSA diagnosis as the predictor, while controlling for the above covariates, regardless of their univariate associations with these asthma outcomes.

Secondly, data from subjects with diagnosed OSA were separately tested among each group, for associations of CPAP use with asthma step or severe asthma as the dependent variables. These multivariate logistic regression models were adjusted only for obesity, due to the small sample size of CPAP users, particularly in the older.

Statistical computations were conducted using SAS software Version 9.2 (SAS Institute, Cary, NC). A two-sided Pvalue $<0.05$ was required for statistical significance. Trends were noted when $P$-values ranged $0.05-0.10$.

\section{Results}

Among 1,026 subjects invited to participate, 952 (93\%) agreed and completed the survey. Of these, 64 subjects had comorbid lung disease and were excluded from the analyses.

For the initial analysis, among 140 (36 older and 104 younger) subjects with previously diagnosed OSA, those 75 (16 older and 59 younger subjects) on treatment at the time of survey were excluded from analyses, as beneficial effects of CPAP treatment for OSA on asthma have been reported
$[12,13]$. Among the remaining 813 subjects, 154 (19\%) were elderly and $659(81 \%)$ young, among whom the main results are reported. The subsequent analysis encompassed solely the 140 subjects with diagnosed OSA, regardless of their treatment status at the time of survey.

3.1. Phenotypic Characteristics of Older and Younger Asthma Subjects. Table 1 presents the demographic, physiologic, and clinical characteristics of the two groups. As compared to the young, older individuals had later onset of asthma symptoms and longer duration of physician-established diagnosis. They exhibited several indices of worse disease control, including physiologic measures and more frequent use of inhaled corticosteroid (ICS) at the time of survey. Older asthmatics had a higher prevalence of nasal polyps and GERD and a lower prevalence of psychiatric diseases. No statistically significant differences emerged in the other clinical variables presented (all $P>0.10$ ). Table 2 depicts the distribution of asthma severity step and severe asthma (step 3 or 4 ) among the older and young groups. As before, when accounting for symptoms, a tendency towards higher step category was seen in the older group, and a significantly larger proportion of older subjects ( $49 \%$ versus $39 \%, \chi^{2}=5.53, P=0.02$ ) were in the severe asthma category. When evaluating the pattern of asthma symptoms, in comparison to the young, older subjects had similar frequencies of persistent daytime symptoms (31\% versus $35 \%, \chi^{2}=0.77, P=0.38$ ), but they less often had nighttime symptoms ( $29 \%$ versus $39 \%, \chi^{2}=5.50, P=0.02$ ).

3.2. OSA Diagnosis and Symptoms in the Older and Younger Asthma Subjects. Table 3 presents the OSA diagnosis (clinically-diagnosed and untreated), SA-SDQ scores, and responses on its symptom-items. A larger proportion of older as opposed to younger subjects had OSA (13\% versus 7\%, $P=0.01)$; likewise, the mean SA-SDQ scores were higher in the older than in the young, and a higher proportion of older subjects ( $34 \%$ versus $25 \%, P=0.03$ ) achieved scores placing them at high risk for OSA, as defined by previously validated cutoffs [19]. Among individual SA-SDQ symptom items, witnessed apneas tended to be more prevalent in older patients who also had a significantly increased prevalence of current/history of hypertension; there was a lower prevalence of gasping arousals in the older relative to the younger patients.

\subsection{Associations of Clinically-Diagnosed and Untreated OSA} with Asthma Severity in the Older and Younger Asthma Subjects. Among older patients, in univariate ordinal logistic regression analyses (Table 4), statistically significant associations of asthma step with OSA and a history of GERD were noted, and trends were observed with BMI and rhinitis. In contrast, age, gender, African-American race, chronic sinusitis, nasal polyps, and a psychiatric history were not significantly associated with asthma step. Associations with OSA were of similar magnitude in the older and younger subjects. When examining severe asthma (Table 5), significant associations were also noted with OSA and GERD, and the 
TABLE 1: Demographic and physiologic characteristics, medical history, and medication use for older and younger asthma subjects.

\begin{tabular}{|c|c|c|c|}
\hline \multirow{2}{*}{ Characteristic } & \multicolumn{2}{|c|}{ Mean \pm SD, or Number (\%) of Subjects } & \multirow{2}{*}{$P$ value } \\
\hline & Older $(n=154)$ & Younger $(n=659)$ & \\
\hline Age (y) & $66 \pm 4$ & $42 \pm 11$ & $<0.0001$ \\
\hline Gender (female) & $95(62 \%)$ & $448(68 \%)$ & 0.14 \\
\hline BMI $\left(\mathrm{kg} \times \mathrm{m}^{-2}\right)$ & $29 \pm 6$ & $29 \pm 7$ & 0.36 \\
\hline$<25$ & $38(25 \%)$ & $214(32 \%)$ & \\
\hline $25-29.9$ & $52(34 \%)$ & $204(31 \%)$ & 0.17 \\
\hline$\geq 30$ & $64(42 \%)$ & $241(37 \%)$ & \\
\hline Race & & & 0.65 \\
\hline African-American & $7(5 \%)$ & $35(5 \%)$ & \\
\hline White & $145(94 \%)$ & $598(91 \%)$ & \\
\hline Others* & $2(1 \%)$ & $26(4 \%)$ & \\
\hline Current smokers & $4(3 \%)$ & $33(5 \%)$ & 0.28 \\
\hline Age of asthma onset (y) & $39 \pm 21$ & $22 \pm 15$ & $<0.0001$ \\
\hline Age at physician-established asthma diagnosis (y) & $41 \pm 20$ & $23 \pm 16$ & $<0.0001$ \\
\hline $\mathrm{FEV}_{1} \%$ predicted & $87 \pm 19$ & $94 \pm 19$ & 0.0002 \\
\hline FVC\% predicted & $84 \pm 16$ & $93 \pm 16$ & $<0.0001$ \\
\hline $\mathrm{FEV}_{1} / \mathrm{FVC}$ & $73 \pm 9$ & $77 \pm 9$ & $<0.0001$ \\
\hline $\mathrm{FEF}_{25-75} \%$ predicted & $56 \pm 27$ & $71 \pm 31$ & $<0.0001$ \\
\hline History of rhinitis & $137(89 \%)$ & $598(91 \%)$ & 0.50 \\
\hline History of chronic sinusitis & $54(35 \%)$ & $192(29 \%)$ & 0.15 \\
\hline History of nasal polyps & $32(21 \%)$ & $88(13 \%)$ & 0.02 \\
\hline History of GERD & $84(55 \%)$ & $285(43 \%)$ & 0.01 \\
\hline History of psychiatric disease & $29(19 \%)$ & $190(29 \%)$ & 0.01 \\
\hline Using inhaled corticosteroid (ICS) & $132(86 \%)$ & $500(76 \%)$ & 0.008 \\
\hline Using oral corticosteroid & $16(10 \%)$ & $54(8 \%)$ & 0.38 \\
\hline Using inhaled long-acting bronchodilator & $97(63 \%)$ & $379(58 \%)$ & 0.22 \\
\hline Using antileukotriene agents & $32(21 \%)$ & $182(28 \%)$ & 0.08 \\
\hline Using inhaled anticholinergic & $10(6 \%)$ & $49(7 \%)$ & 0.69 \\
\hline Using theophylline & $4(3 \%)$ & $13(2 \%)$ & 0.54 \\
\hline
\end{tabular}

Definition of abbreviations: SD: standard deviation; BMI: body mass index; $\mathrm{FEV}_{1} \%$ : forced expiratory volume in first second; FVC\%: forced vital capacity; $\mathrm{FEF}_{25-75} \%$ : forced expiratory flow between $25 \%$ and $75 \%$ of vital capacity (all of these physiologic variables are expressed as percentages of predicted values); GERD: gastroesophageal reflux disease.

* Included Asians, Hawaiian/Pacific Islander, and American Indians/Alaskans.

TABLE 2: Distribution of asthma severity step and severe asthma (step 3 or 4) among older and younger asthma subjects.

\begin{tabular}{lccc}
\hline & $\begin{array}{c}\text { Older }(n=154) \\
\text { number }(\%)\end{array}$ & $\begin{array}{c}\text { Younger }(n=659) \\
\text { number }(\%)\end{array}$ & $P$ value \\
\hline Asthma step & & & \\
1 & $64(42 \%)$ & $312(47 \%)$ & 0.08 \\
2 & $14(9 \%)$ & $90(14 \%)$ & \\
3 & $44(29 \%)$ & $138(21 \%)$ & \\
4 & $32(21 \%)$ & $119(18 \%)$ & \\
Severe asthma & $76(49 \%)$ & $257(39 \%)$ & 0.02 \\
\hline
\end{tabular}

relationship with OSA was of greater magnitude in the older than in the young.

In a multivariate model (Table 6) that included all the above variables as covariates, only OSA was significantly associated with asthma severity step: having an OSA diagnosis increased the odds of a worse asthma severity step on average by $191 \%$ (OR $=2.91,95 \%$ confidence interval $[1.15-$ 7.36]), independent of the other characteristics. Associations of OSA with asthma step in older subjects seemed of greater magnitude than in the younger subjects. In a reiteration of this model using severe asthma as the dependent variable (Table 7), much more robust associations with OSA were observed in the older than in the younger subjects: independent of covariates, an OSA diagnosis raised the likelihood of severe asthma on average by $567 \%$ (OR $=6.67,95 \%$ confidence interval [1.74-25.56]) in the older subjects versus $161 \%(2.61[1.28-5.33])$ in the younger subjects.

3.4. Pattern of Asthma Symptoms and Their Associations with Clinically-Diagnosed and Untreated OSA in Older and Younger Asthma Subjects. A differential expression of the relationships between daytime or nighttime asthma symptoms with OSA was noted (Table 8): in the older subjects, nighttime asthma symptoms were primarily related to OSA (4.56 [1.55-13.43]), whereas in the younger subjects daytime 
TABLE 3: OSA (clinically-diagnosed and untreated), SA-SDQ scores, and frequencies of individual symptoms (when present with any frequency), in older and younger asthma subjects.

\begin{tabular}{|c|c|c|c|}
\hline & \multicolumn{2}{|c|}{ Mean \pm SD or number (\%) of subjects } & \multirow{2}{*}{$P$ value } \\
\hline & Older $(n=154)$ & Younger $(n=659)$ & \\
\hline OSA & $20(13 \%)$ & $45(7 \%)$ & 0.01 \\
\hline SA-SDQ score & $30.2 \pm 6.4$ & $27.7 \pm 7.6$ & $<0.0001$ \\
\hline Snoring & $126(82 \%)$ & $511(78 \%)$ & 0.25 \\
\hline Habitual snoring* & $37(24 \%)$ & $172(26 \%)$ & 0.60 \\
\hline Witnessed apneas & $50(32 \%)$ & $167(25 \%)$ & 0.07 \\
\hline Sudden gasping arousals & $48(31 \%)$ & $276(42 \%)$ & 0.01 \\
\hline Excessive sweating at night & $109(71 \%)$ & $481(73 \%)$ & 0.58 \\
\hline Current or history of hypertension & $87(56 \%)$ & $182(28 \%)$ & $<0.0001$ \\
\hline Nasal congestion during sleep & $118(77 \%)$ & $485(74 \%)$ & 0.44 \\
\hline Snoring worse when supine & $103(67 \%)$ & $433(66 \%)$ & 0.78 \\
\hline Snoring worse after alcohol & $51(33 \%)$ & $236(36 \%)$ & 0.53 \\
\hline
\end{tabular}

Definition of abbreviations: OSA: obstructive sleep apnea; SA-SDQ: Sleep Apnea scale of the Sleep Disorders Questionnaire (range 12-60); ${ }^{*}$ Habitual snoring: snoring occurring "usually" or "always" (responses of 4 or 5 on the SA-SDQ).

TABLE 4: Univariate associations of asthma severity step with OSA (clinically-diagnosed and untreated) and other traditional factors of asthma control, in the older and younger asthma subjects.

\begin{tabular}{|c|c|c|c|c|}
\hline & \multicolumn{2}{|l|}{ Older $(n=154)$} & \multicolumn{2}{|l|}{ Younger $(n=659)$} \\
\hline & Odds ratio[95\% confidence interval] & $P$ value & Odds ratio [95\% confidence interval] & $P$ value \\
\hline OSA & $3.44[1.43-8.27]$ & $<0.0001$ & $3.61[2.07-6.31]$ & $<0.0001$ \\
\hline Age & $1.04[0.97-1.11]$ & 0.30 & $1.01[1.00-1.02]$ & 0.12 \\
\hline Gender (female versus male) & $0.97[0.54-1.77]$ & 0.93 & $1.35[1.00-1.83]$ & 0.05 \\
\hline BMI (categorized) & $1.37[0.95-1.98]$ & 0.09 & $1.84[1.54-2.20]$ & $<0.0001$ \\
\hline African-American (versus all others) & $1.90[0.48-7.55]$ & 0.36 & $4.04[2.14-7.60]$ & $<0.0001$ \\
\hline Rhinitis & $0.43[0.17-1.09]$ & 0.08 & $0.27[0.17-0.44]$ & $<0.0001$ \\
\hline Chronic sinusitis & $0.67[0.36-1.23]$ & 0.20 & $0.93[0.68-1.28]$ & 0.67 \\
\hline Nasal polyps & $0.92[0.45-1.88]$ & 0.82 & $1.35[0.90-2.04]$ & 0.15 \\
\hline GERD & $1.94[1.08-3.51]$ & 0.03 & $1.64[1.23-2.18]$ & 0.0007 \\
\hline Psychiatric disease & $1.26[0.60-2.62]$ & 0.54 & $1.50[1.10-2.04]$ & 0.01 \\
\hline
\end{tabular}

Definition of abbreviations: OSA: obstructive sleep apnea; BMI: body mass index $\left(\mathrm{kg} / \mathrm{m}^{2}\right)$; GERD: gastroesophageal reflux disease.

TABLE 5: Univariate associations of severe asthma (step 3 or 4) with OSA (clinically-diagnosed and untreated) and other traditional factors of asthma control, in the older and younger asthma subjects.

\begin{tabular}{|c|c|c|c|c|}
\hline & \multicolumn{2}{|l|}{ Older $(n=154)$} & \multicolumn{2}{|l|}{ Younger $(n=659)$} \\
\hline & Odds ratio [95\% confidence interval] & $P$ value & Odds ratio [95\% confidence interval] & $P$ value \\
\hline OSA & $7.20[2.02-25.74]$ & 0.002 & $4.26[2.19-8.28]$ & $<0.0001$ \\
\hline Age & $1.04[0.97-1.11]$ & 0.30 & $1.01[1.00-1.02]$ & 0.12 \\
\hline Gender (female versus male) & $0.97[0.54-1.77]$ & 0.93 & $1.35[1.00-1.83]$ & 0.05 \\
\hline BMI (categorized) & $1.37[0.95-1.98]$ & 0.09 & $1.84[1.54-2.20]$ & $<0.0001$ \\
\hline African-American (versus all others) & $1.90[0.48-7.55]$ & 0.36 & $4.04[2.14-7.60]$ & $<0.0001$ \\
\hline Rhinitis & $0.43[0.17-1.09]$ & 0.08 & $0.27[0.17-0.44]$ & $<0.0001$ \\
\hline Chronic sinusitis & $0.67[0.36-1.23]$ & 0.20 & $0.93[0.68-1.28]$ & 0.67 \\
\hline Nasal polyps & $0.92[0.45-1.88]$ & 0.82 & $1.35[0.90-2.04]$ & 0.15 \\
\hline GERD & $1.94[1.08-3.51]$ & 0.03 & $1.64[1.23-2.18]$ & 0.0007 \\
\hline Psychiatric disease & $1.26[0.60-2.62]$ & 0.54 & $1.50[1.10-2.04]$ & 0.01 \\
\hline
\end{tabular}

Definition of abbreviations: OSA: obstructive sleep apnea; BMI: body mass index $\left(\mathrm{kg} / \mathrm{m}^{2}\right)$; GERD: gastroesophageal reflux disease. 
TABLE 6: Multivariate associations of asthma severity step with OSA (clinically-diagnosed and untreated) and other traditional factors of asthma control, in the older and younger asthma subjects.

\begin{tabular}{|c|c|c|c|c|}
\hline & \multicolumn{2}{|l|}{ Older $(n=154)$} & \multicolumn{2}{|l|}{ Younger $(n=659)$} \\
\hline & Odds ratio [95\% confidence interval] & $P$ value & Odds ratio [95\% confidence interval] & $P$ value \\
\hline OSA & $2.91[1.15-7.36]$ & 0.02 & $2.07[1.14-3.75]$ & 0.02 \\
\hline Age & $1.03[0.96-1.10]$ & 0.48 & $1.00[0.99-1.02]$ & 0.89 \\
\hline Gender (female versus male) & $0.89[0.46-1.74]$ & 0.74 & $1.45[1.06-1.99]$ & 0.02 \\
\hline BMI (categorized) & $1.22[0.82-1.81]$ & 0.32 & $1.60[1.32-1.93]$ & $<0.0001$ \\
\hline African-American (versus all others) & $0.76[0.17-3.43]$ & 0.72 & $3.08[1.60-5.93]$ & 0.0008 \\
\hline Rhinitis & $0.48[0.19-1.25]$ & 0.14 & $0.36[0.22-0.59]$ & $<0.0001$ \\
\hline Chronic Sinusitis & $0.60[0.29-1.24]$ & 0.17 & $0.88[0.62-1.26]$ & 0.49 \\
\hline Nasal Polyps & $1.34[0.55-3.26]$ & 0.52 & $1.26[0.79-1.95]$ & 0.33 \\
\hline GERD & $1.58[0.86-2.92]$ & 0.14 & $1.22[0.89-1.67]$ & 0.22 \\
\hline Psychiatric disease & $1.33[0.60-2.97]$ & 0.48 & $1.31[0.94-1.82]$ & 0.11 \\
\hline
\end{tabular}

Definition of abbreviations: OSA: obstructive sleep apnea; BMI: body mass index $\left(\mathrm{kg} / \mathrm{m}^{2}\right)$; GERD: gastroesophageal reflux disease.

TABLE 7: Multivariate associations of severe asthma (step 3 or 4) with OSA (clinically-diagnosed and untreated) and other traditional factors of asthma control, in the older and younger asthma subjects.

\begin{tabular}{|c|c|c|c|c|}
\hline & \multicolumn{2}{|l|}{ Older $(n=154)$} & \multicolumn{2}{|l|}{ Younger $(n=659)$} \\
\hline & Odds ratio [95\% confidence interval] & $P$ value & Odds ratio [95\% confidence interval] & $P$ value \\
\hline OSA & $6.67[1.74-25.56]$ & 0.006 & $2.61[1.28-5.33]$ & 0.008 \\
\hline Age & $1.06[0.98-1.14]$ & 0.17 & $1.01[0.99-1.02]$ & 0.45 \\
\hline Gender (female versus male) & $1.32[0.61-2.86]$ & 0.49 & $1.48[1.03-2.11]$ & 0.04 \\
\hline BMI (categorized) & $1.06[0.68-1.65]$ & 0.81 & $1.49[1.20-1.84]$ & 0.0003 \\
\hline African-American (versus all others) & $1.89[0.27-13.24]$ & 0.52 & $4.26[1.89-9.59]$ & 0.0005 \\
\hline Rhinitis & $0.40[0.12-1.28]$ & 0.12 & $0.45[0.25-0.81]$ & 0.007 \\
\hline Chronic sinusitis & $0.38[0.16-0.91]$ & 0.03 & $0.81[0.54-1.22]$ & 0.31 \\
\hline Nasal polyps & $1.73[0.60-4.96]$ & 0.31 & $1.32[0.78-2.23]$ & 0.30 \\
\hline GERD & $1.35[0.67-2.71]$ & 0.41 & $1.30[0.91-1.85]$ & 0.16 \\
\hline Psychiatric disease & $1.68[0.65-4.33]$ & 0.28 & $1.05[0.72-1.54]$ & 0.81 \\
\hline
\end{tabular}

Definition of abbreviations: OSA: obstructive sleep apnea; BMI: body mass index $\left(\mathrm{kg} / \mathrm{m}^{2}\right)$; GERD: gastroesophageal reflux disease.

TABLE 8: Multivariate associations of persistent daytime and nighttime asthma symptoms with OSA (clinically-diagnosed and untreated) with adjustment for age, gender, race (African-American versus. all others), rhinitis, chronic sinusitis, nasal polyps, gastroesophageal reflux disease, and psychiatric disease, in the older and younger asthma subjects.

\begin{tabular}{|c|c|c|c|c|}
\hline & \multicolumn{2}{|l|}{ Older $(n=154)$} & \multicolumn{2}{|l|}{ Younger $(n=659)$} \\
\hline & Odds ratio [ $95 \%$ confidence interval] & $P$ value & Odds ratio [95\% confidence interval] & $P$ value \\
\hline Persistent daytime symptoms & $2.00[0.71-5.65]$ & 0.19 & $2.66[1.32-5.35]$ & 0.006 \\
\hline Persistent nighttime symptoms & $4.56[1.55-13.43]$ & 0.006 & $1.35[0.70-2.63]$ & 0.37 \\
\hline
\end{tabular}

asthma symptoms were associated with OSA (2.66 [1.32$5.32])$, both after adjustment for the same variables shown in Tables 6 and 7.

3.5. Relationships of Asthma Severity with CPAP Use among Older and Younger Subjects with Clinically-Diagnosed OSA. Among clinically-diagnosed OSA subjects $(n=140)$, the frequency of CPAP use was not significantly different between the older and younger groups (21\% versus $31 \%, \chi^{2}$ $=1.62, P=0.20$ ). In older subjects, with adjustment for BMI, CPAP use was associated with a reduced likelihood of worse asthma step by $86 \%(0.14$ [0.04-0.56], $P=0.005)$ and of severe asthma by $91 \%(0.09$ [0.02-0.49], $P=0.005)$; these relationships were of greater magnitude in older subjects than in younger subjects, where CPAP use attenuated the likelihood of worse asthma step by $58 \%(0.42$ [0.20-0.88], $P=0.02)$ and that of severe asthma by $57 \%(0.43$ [0.18-1.03], $P=0.06)$.

\section{Discussion}

This analysis of a large clinic-based sample of patients with asthma shows for the first time that older as compared to younger asthmatics have worse asthma control and that poor control in older subjects may depend on comorbid OSA more than it does in younger subjects. Moreover, 
CPAP use attenuated the likelihood of worse asthma control, statistically, more robustly in older than in younger subjects. In marked contrast to OSA symptoms, traditionally recognized risk factors for asthma such as BMI, female gender, African-American race, rhinitis, and GERD showed little or no independent predictive value for asthma control among older persons. Collectively, these data suggest that underlying OSA may contribute to worse asthma control, particularly in the older patients, independent of other known asthma aggravators.

This clinic-based asthma sample is likely representative of older asthma patients, including those with unrecognized OSA, who are managed in specialty clinic settings. There was a high participation rate in our survey study (95\%). Obesity rates were consistent with current estimates of obesity in this age group [23]. Mean duration of asthma was comparable with that reported in other studies [24]. Subjects demonstrated a higher $\mathrm{FEV}_{1} / \mathrm{FVC}$ ratio and much higher use of inhaled corticosteroids than what has been reported previously $[2,4]$, indicating appropriate use of treatment guidelines for asthma control in our sample. The high prevalence of patients with rhinitis (88\%) reflects that this sample was recruited in good part from Allergy clinics. Rhinitis was not associated with asthma step in our population, likely due to its rigorous management by expert providers, which counteracted its detrimental influence on asthma control. Smoking was remarkably infrequent in our sample as compared to others [25], which may reflect a historical trend toward lower smoking rates or more effective education and interventions in two university clinic settings. Nonetheless, this finding supports the absence of confounding by comorbid chronic obstructive lung disease.

Despite vigorous management, nearly half (49\%) of our older subjects had worse asthma control (severe asthma: steps 3 and 4) as compared with 39\% in the younger group, consistent with other reports [26]. This finding suggests that other factors for poor control of asthma, besides those usually recognized, may be at play. One explanation may be that older patients have worse physiological changes compared with younger asthmatics; however, no age effect was found in intraluminal obstruction and subepithelial collagen in a study of individuals who died from asthma [27]. Our data suggest an alternate explanation for this relationship.

We found a significant association of diagnosed OSA with worse asthma control (asthma step) among older patients. Associations of potential clinical significance have been identified between asthma and OSA, such that treatment for comorbid OSA improved asthma symptoms [12, 13, 28], use of rescue bronchodilator, peak expiratory flow rates [12], and disease-specific quality of life [29]. However, these data came from younger subjects, and to our knowledge, our study is the first to extend identification of OSA as a potential adverse contributor to asthma control to the aged. While asthma is an important cause of morbidity and mortality in older individuals, in regard to sleep and respiratory diseases in older persons, little data are available, pertaining mainly to disrupted sleep. Older patients with chronic airway obstruction, relative to controls, have a higher prevalence and greater severity of sleep difficulties and morning tiredness
[10]. Furthermore, among older individuals with obstructive lung disease, sleep quality is worse in asthmatics than in individuals with COPD and chronic bronchitis [10].

For the first time, we report that the association of OSA with worse asthma control was of greater magnitude in older than in younger individuals (Tables 6 and 7) and, likewise, that CPAP use more robustly in the older than in the young attenuated the likelihood of worse asthma control. It is known that older adults are at increased risk for OSA and for more severe disease, which may be an explanation for our observation. Prevalence estimates for OSA among persons over 65 years of age, compared to those for the middle aged, are approximately 2-3 times higher [30]. In a large cohort of healthy older persons, the prevalence of OSA as defined by apnea hypopnea index (AHI) $>15$ respiratory events/hr was $53 \%$, and $37 \%$ had severe OSA (AHI > 30) [31]. Our sample demonstrates similar rates of snoring with a sample of 134 older subjects of similar age (mean $64.1 \pm$ 9.1 years) and BMI $\left(29.3 \pm 5.3 \mathrm{~kg} / \mathrm{m}^{2}\right)$ [32]. Furthermore, in the most recent Wisconsin Sleep Cohort data, regardless of gender and BMI strata, the oldest group (50-70 years old) consistently demonstrated higher OSA (AHI $\geq 5$ events/h) prevalence including that of clinically-significant $(\mathrm{AHI} \geq$ 5 and daytime sleepiness) and of more severe (AHI $\geq 15$ and daytime sleepiness) disease [33]. Age-related changes in the upper airway anatomy have been shown, including an increase in the soft palate length and parapharyngeal fat pads independent of BMI, as well as a decrease in the upper airway size $[34,35]$. Aging also affects upper airway function by decreasing the genioglossus's response to negative pressure, a greater reduction in genioglossus and tensor palatini activity at sleep onset, and an increase in pharyngeal collapsibility and resistance independent of BMI and gender [34,36,37]. These effects may be compounded in older asthmatics by the effects of sleep on their lung properties-important determinants of upper airway patency during sleep [38]. There is an augmented decline in functional residual capacity (FRC) during sleep in patients with asthma: as compared to normal controls, among asthmatics, the FRC is significantly reduced while sleeping supine than during supine wakefulness. Loss of lung elastic recoil may reduce the effectiveness of lung volume stabilizing the upper airway during sleep [38]. Furthermore, in elderly asthmatics, an association between FRC (estimating degree of hyperinflation) and duration of asthma, as well as an inverse relationship of $\mathrm{FEV}_{1} \%$ predicted with duration of asthma has been shown; however, the former was independent of the degree of airflow limitation, suggesting that the duration of asthma is associated with both the degree of airflow limitation and hyperinflation [39]. This study suggested that with longer asthma duration, in time these abnormalities may become irreversible, as a reflection of distal airway and/or parenchymal changes as well as proximal airway remodeling [39]. Conversely, in regards to CPAP use, one predictor of beneficial effects of CPAP is the severity of disease. In one large study, the oxygen desaturation index (ODI) showed the strongest association with long-term adherence to CPAP; age was not a detrimental factor [40]. 
PSG in young asthma individuals of different severities and controls did find lower mean nocturnal $\mathrm{SaO}_{2}$ and higher AHIs with more severe asthma, compared with controls [41]. Therefore, a higher severity of disease, particularly its degree of hypoxemia in elderly asthma patients, could be a factor in their more reported benefit with CPAP.

Another interesting and intriguing observation from this study is the differential pattern of associations of OSA observed with asthma symptoms: more with nighttime in older and more with daytime in younger individuals (Table 8). This has to be better understood in future studies, but one possibility remains that sleep in older patients with chronic airway obstruction being marked by more disruptions and awakenings [10] may render them more aware of their nighttime asthma symptoms than the young.

How OSA can worsen asthma in general remains unknown, but there are several plausible pathways. The concept of a relationship between upper and lower airways called the integrated airway [42] is used to describe an inflammatory process within a continuous airway as opposed to distinct pathologies [43] and may also underlie the interaction of OSA with asthma. Repetitive upper airway obstruction results in intrathoracic pressure swings, frequent arousals, and intermittent hypoxemia that contribute to an inflammatory milieu, as demonstrated through associations with cardiovascular and cerebrovascular diseases [44, 45]. Other putative mechanisms include SDB-induced resistive loading [46] of an already challenged lower airways system during sleep [47], enhanced vagal tone during obstructive events [28], increased nonspecific bronchial reactivity [48, 49], altered chemical arousal thresholds [50], and upper airway occlusion [51], all of which may promote bronchoconstriction. Although experimental human studies of intermittent hypoxia are lacking, exposure to sustained hypoxia led to cough suppression [52] and impaired symptom perception in individuals with asthma [53]. OSA could also promote GERD [54], which is a well-recognized trigger of asthma [55].

Our data suggest a potential role of OSA in asthma control independent of other factors known to worsen this disease, such as obesity, particularly in the elderly $[56,57]$. Studies of the relationship between obesity and asthma in older persons are scarce and do not account for OSA as a potential mediator, though obesity is an important risk factor for OSA [30]. In a population-based longitudinal study of older Norwegians, a U-shaped association between asthma and BMI was found [58]. However, our study adds new evidence to suggest that much of the association between obesity and asthma may in fact be explained by OSA. In our older subjects, accounting for OSA completely attenuated (Tables 6 and 7) the trends of BMI with asthma initially noted in univariate analyses (Tables 4 and 5). One other study that systematically assessed OSA syndrome in difficult-tocontrol asthmatics did report an increased risk for OSA (3.1 (1.1-9.0)), less severe airway obstruction, and eosinophilic inflammation and concluded that other factors, rather than airway inflammation alone, explain the relationship between obesity and asthma [59].

Among limitations to our study, we relied on the use of a questionnaire-based approach (SA-SDQ) to evaluate
OSA symptoms prospectively and of previously clinicallydocumented diagnosis of OSA. Additionally, owing to lack of availability and heterogeneity of testing we did not have meaningful PSG data available. Costs of prospective PSG would have been prohibitive for an early-stage investigation of this size, and selection bias might well have been more prominent, as far fewer than $93 \%$ of approached patients would have agreed to participate. The SA-SDQ has been validated in a large sample of sleep patients with high internal validity, good sensitivity, and specificity [19]. Although lower threshold scores than those used herein have been validated in patients with epilepsy [60], application of those lower thresholds to patients with pulmonary fibrosis reduced the performance of the survey instrument, despite retention of a good correlation between SA-SDQ and OSA severity [61]. These data suggest that the original cutoffs [19], which we used in our study, may be more suitable for patients with chronic lung diseases.

The cross-sectional design of this study limits conclusions about causality. Although asthma may be a risk factor for the development of OSA [62], our data fit with those from interventional studies $[12,13,28,29]$ and plausible mechanisms, as reviewed above, to suggest a detrimental effect of OSA on asthma control. Lastly, our sample included subjects aged up to 75 years, a restriction imposed by the design of the parent study. Our anecdotal observation conducting this survey is that there were quite small numbers of patients over 75 years of age attending our tertiary Allergy and Pulmonary clinics; therefore, we do not feel that this age restriction is likely to have had substantial impact on our findings. These patients may have unique comorbidity and cognitive profiles making them suitable for inclusion in future studies, specifically targeted to the older asthma patient population.

In conclusion, this first study of asthma and its relationship with OSA among well-characterized patients finds in older individuals worse indices of disease control than in the young. It also shows associations of OSA diagnosis with worse asthma control indices that were independent of obesity and other recognized asthma aggravators and in great part attenuated by CPAP use. These associations were of greater magnitude in the older than in the younger subjects, suggesting that the former may draw greater benefit from treating OSA. These data are correlative and cannot prove causation, but they raise the possibility that in many cases, OSA may be an unrecognized contributor to asthma control in older persons. If so, identification and treatment of OSA may improve asthma control particularly in these patients.

\section{Authors' Contribution}

Mihaela Teodorescu, Mihai C. Teodorescu, and Ronald D. Chervin were responsible for the conception and design of the paper. Mihaela Teodorescu, David A. Polomis, Jessica E. Fedie, and Mihai C. Teodorescu were responsible for the acquisition of subjects and/or data. Mihaela Teodorescu and Ronald E. Gangnon were responsible for data analysis. Mihaela Teodorescu, Ronald E. Gangnon, Flavia B. Consens, 
Ronald D. Chervin, and Mihai C. Teodorescu were responsible for the interpretation of the data. Mihaela Teodorescu and Mihai C. Teodorescu were responsible for the drafting of the paper. Ronald E. Gangnon, Jessica E. Fedie, Flavia B. Consens, and Ronald D. Chervin were responsible for the critical review of the paper.

\section{Acknowledgments}

This work was conducted at the University of Michigan Health System, Ann Arbor, MI and the University of Wisconsin, Madison, WI. The authors are grateful to all patients for their participation in the survey, as well as to all providers in clinics at the two institutions for assisting with patient recruitment. This study was funded by the University of Michigan General Clinical Research Center (MO1 RR00042); University of Michigan, Department of Neurology Training Grant (T32 NS007222); University of Wisconsin School of Medicine and Public Health, Department of Medicine; the Medical Education and Research Committee-New Investigator Award, University of Wisconsin School of Medicine and Public Health, Madison, WI; 1UL1RR025011 from the Clinical and Translational Science Award (CTSA) program of the National Center for Research Resources, National Institutes of Health for asthma-sleep apnea research; and with additional resources from the William S. Middleton Memorial Veterans Hospital, Madison, WI (to Dr. Mihaela Teodorescu).

\section{References}

[1] P. Barua and M. S. O’Mahony, "Overcoming gaps in the management of asthma in older patients: new insights," Drugs and Aging, vol. 22, no. 12, pp. 1029-1059, 2005.

[2] K. Parameswaran, A. J. Hildreth, D. Chadha, N. P. Keaney, I. K. Taylor, and S. K. Bansal, "Asthma in the elderly: underperceived, underdiagnosed and undertreated; a community survey," Respiratory Medicine, vol. 92, no. 3, pp. 573-577, 1998.

[3] P. L. Enright, "The diagnosis and management of asthma is much tougher in older patients," Current Opinion in Allergy and Clinical Immunology, vol. 2, no. 3, pp. 175-181, 2002.

[4] P. L. Enright, R. A. Kronmal, M. W. Higgins, M. B. Schenker, and E. F. Haponik, "Prevalence and correlates of respiratory symptoms and disease in the elderly," Chest, vol. 106, no. 3, pp. 827-834, 1994.

[5] S. S. Braman, "Asthma in the elderly," Clinics in Geriatric Medicine, vol. 19, no. 1, pp. 57-75, 2003.

[6] G. B. Diette, J. A. Krishnan, F. Dominici et al., "Asthma in older patients: factors associated with hospitalization," Archives of Internal Medicine, vol. 162, no. 10, pp. 1123-1132, 2002.

[7] Center for Disease Control and Prevention, Asthma Surveillance Data, http://www.cdc.gov/asthma/asthmadata.htm.

[8] J. Moorman and D. Mannino, "Increasing U.S. asthma mortality rates: who is really dying?” Journal of Asthma, vol. 38, no. 1, pp. 65-71, 2001.

[9] P. G. Gibson, V. M. McDonald, and G. B. Marks, "Asthma in older adults," The Lancet, vol. 376, no. 9743, pp. 803-813, 2010.

[10] R. Antonelli Incalzi, R. Pistelli, C. Imperiale et al., "Effects of chronic airway disease on health status of geriatric patients,"
Aging Clinical and Experimental Research, vol. 16, no. 1, pp. 2633,2004

[11] S. Ancoli-Israel, D. F. Kripke, M. R. Klauber, W. J. Mason, R. Fell, and O. Kaplan, "Sleep-disordered breathing in communitydwelling elderly," Sleep, vol. 14, no. 6, pp. 486-495, 1991.

[12] C. Shu Chan, A. J. Woolcock, and C. E. Sullivan, "Nocturnal asthma: role of snoring and obstructive sleep apnea," American Review of Respiratory Disease, vol. 137, no. 6, pp. 1502-1504, 1988.

[13] T. U. Ciftci, B. Ciftci, S. Firat Guven, O. Kokturk, and H. Turktas, "Effect of nasal continuous positive airway pressure in uncontrolled nocturnal asthmatic patients with obstructive sleep apnea syndrome," Respiratory Medicine, vol. 99, no. 5, pp. 529-534, 2005.

[14] A. ten Brinke, P. J. Sterk, A. A. M. Masclee et al., "Risk factors of frequent exacerbations in difficult-to-treat asthma," European Respiratory Journal, vol. 26, no. 5, pp. 812-818, 2005.

[15] M. Teodorescu, F. B. Consens, W. F. Bria et al., "Correlates of daytime sleepiness in patients with asthma," Sleep Medicine, vol. 7, no. 8, pp. 607-613, 2006.

[16] M. Teodorescu, F. B. Consens, W. F. Bria et al., "Predictors of habitual snoring and obstructive sleep apnea risk in patients with asthma," Chest, vol. 135, no. 5, pp. 1125-1132, 2009.

[17] M. Teodorescu, D. A. Polomis, S. V. Hall et al., "Association of obstructive sleep apnea risk with asthma control in adults," Chest, vol. 138, no. 3, pp. 543-550, 2010.

[18] Standards for the diagnosis and care of patients with chronic obstructive pulmonary disease (COPD) and asthma, "This official statement of the American Thoracic Society was adopted by the ATS Board of Directors," The American Review of Respiratory Disease, vol. 136, no. 1, pp. 225-244, 1987.

[19] A. B. Douglass, R. Bornstein, G. Nino-Murcia et al., “The Sleep Disorders Questionnaire I: creation and multivariate structure of SDQ," Sleep, vol. 17, no. 2, pp. 160-167, 1994.

[20] US Department of Health and Human Services, National Institute of Health, National asthma education and prevention program: practical guide for the diagnosis and management of asthma, expert panel report 2, http://www.nhlbi.nih.gov.ezproxy.library.wisc.edu/guidelines/ archives/epr-2/index.htm.

[21] C. Janson, W. De Backer, T. Gislason et al., "Increased prevalence of sleep disturbances and daytime sleepiness in subjects with bronchial asthma: a population study of young adults in three European countries," European Respiratory Journal, vol. 9, no. 10, pp. 2132-2138, 1996.

[22] "Expert panel report 3 (EPR-3): guidelines for the diagnosis and management of asthma," Full Report, US Department of Health and Human Services. National Institute of Health, National Heart, Lung and Blood Institute. National Asthma Education and Prevention Program, 2007, http://www.nhlbi.nih.gov/guidelines/asthma/asthgdln.pdf.

[23] D. E. Arterburn, P. K. Crane, and S. D. Sullivan, "The coming epidemic of obesity in elderly Americans," Journal of the American Geriatrics Society, vol. 52, no. 11, pp. 1907-1912, 2004.

[24] L. Rogers, C. Cassino, K. I. Berger et al., "Asthma in the elderly: cockroach sensitization and severity of airway obstruction in elderly nonsmokers," Chest, vol. 122, no. 5, pp. 1580-1586, 2002.

[25] W. C. Bailey, J. M. Richards Jr., C. M. Brooks, S.-J. Soong, and A. L. Brannen, "Features of asthma in older adults," Journal of Asthma, vol. 29, no. 1, pp. 21-28, 1992.

[26] K. Huss, P. L. Naumann, P. J. Mason et al., "Asthma severity, atopic status, allergen exposure, and quality of life in elderly 
persons," Annals of Allergy, Asthma and Immunology, vol. 86, no. 5, pp. 524-530, 2001.

[27] T. R. Bai, J. Cooper, T. Koelmeyer, P. D. Pare, and T. D. Weir, "The effect of age and duration of disease on airway structure in fatal asthma," American Journal of Respiratory and Critical Care Medicine, vol. 162, no. 2 I, pp. 663-669, 2000.

[28] C. Guilleminault, M. A. Quera-Salva, N. Powell et al., "Nocturnal asthma: snoring, small pharynx and nasal CPAP," European Respiratory Journal, vol. 1, no. 10, pp. 902-907, 1988.

[29] C. Lafond, F. Sériès, and C. Lemière, "Impact of CPAP on asthmatic patients with obstructive sleep apnoea," European Respiratory Journal, vol. 29, no. 2, pp. 307-311, 2007.

[30] T. Young, P. E. Peppard, and D. J. Gottlieb, "Epidemiology of obstructive sleep apnea: a population health perspective," American Journal of Respiratory and Critical Care Medicine, vol. 165, no. 9, pp. 1217-1239, 2002.

[31] E. Sforza, F. Roche, C. Thomas-Anterion et al., "Cognitive function and sleep related breathing disorders in a healthy elderly population: the synapse study," Sleep, vol. 33, no. 4, pp. 515-521, 2010.

[32] R. A. Stoohs, H.-C. Blum, M. Haselhorst, H. W. Duchna, C. Guilleminault, and W. C. Dement, "Normative data on snoring: a comparison between younger and older adults," European Respiratory Journal, vol. 11, no. 2, pp. 451-457, 1998.

[33] P. E. Peppard, T. Young, J. H. Barnet et al., "Increasedprevalence of sleep-disordered breathing in adults," American Journal of Epidemiology. In press.

[34] A. Malhotra, Y. Huang, R. Fogel et al., "Aging influences on pharyngeal anatomy and physiology: the predisposition to pharyngeal collapse," American Journal of Medicine, vol. 119, no. 1, pp. 72-e9, 2006.

[35] S. E. Martin, R. Mathur, I. Marshall, and N. J. Douglas, "The effect of age, sex, obesity and posture on upper airway size," European Respiratory Journal, vol. 10, no. 9, pp. 2087-2090, 1997.

[36] M. Eikermann, A. S. Jordan, N. L. Chamberlin et al., "The influence of aging on pharyngeal collapsibility during sleep," Chest, vol. 131, no. 6, pp. 1702-1709, 2007.

[37] C. Worsnop, A. Kay, Y. Kim, J. Trinder, and R. Pierce, "Effect of age on sleep onset-related changes in respiratory pump and upper airway muscle function," Journal of Applied Physiology, vol. 88, no. 5, pp. 1831-1839, 2000.

[38] D. P. White, "The pathogenesis of obstructive sleep apnea: advances in the past 100 years," American Journal of Respiratory Cell and Molecular Biology, vol. 34, no. 1, pp. 1-6, 2006.

[39] C. Cassino, K. I. Berger, R. M. Goldring et al., "Duration of asthma and physiologic outcomes in elderly nonsmokers," American Journal of Respiratory and Critical Care Medicine, vol. 162, no. 4 I, pp. 1423-1428, 2000.

[40] M. Kohler, D. Smith, V. Tippett, and J. R. Stradling, "Predictors of long-term compliance with continuous positive airway pressure," Thorax, vol. 65, no. 9, pp. 829-832, 2010.

[41] J. Y. Julien, J. G. Martin, P. Ernst et al., "Prevalence of obstructive sleep apnea-hypopnea in severe versus moderate asthma," Journal of Allergy and Clinical Immunology, vol. 124, no. 2, pp. 371-376, 2009.

[42] E. O. Meltzer, J. Szwarcberg, and M. W. Pill, "Allergic rhinitis, asthma, and rhinosinusitis: diseases of the integrated airway," Journal of Managed Care Pharmacy, vol. 10, no. 4, pp. 310-317, 2004.
[43] L. Bjermer, “Time for a paradigm shift in asthma treatment: from relieving bronchospasm to controlling systemic inflammation," Journal of Allergy and Clinical Immunology, vol. 120, no. 6, pp. 1269-1275, 2007.

[44] A. S. M. Shamsuzzaman, B. J. Gersh, and V. K. Somers, "Obstructive sleep apnea: implications for cardiac and vascular disease," Journal of the American Medical Association, vol. 290, no. 14, pp. 1906-1914, 2003.

[45] H. K. Yaggi, J. Concato, W. N. Kernan, J. H. Lichtman, L. M. Brass, and V. Mohsenin, "Obstructive sleep apnea as a risk factor for stroke and death," The New England Journal of Medicine, vol. 353, no. 19, pp. 2034-2041, 2005.

[46] E. L. Bijaoui, V. Champagne, P. F. Baconnier, R. John Kimoff, and J. H. T. Bates, "Mechanical properties of the lung and upper airways in patients with sleep-disordered breathing," American Journal of Respiratory and Critical Care Medicine, vol. 165, no. 8, pp. 1055-1061, 2002.

[47] R. D. Ballard, "Sleep, respiratory physiology, and nocturnal asthma," Chronobiology International, vol. 16, no. 5, pp. 565-580, 1999.

[48] C.-C. Lin and C.-Y. Lin, "Obstructive sleep apnea syndrome and bronchial hyperreactivity," Lung, vol. 173, no. 2, pp. 117-126, 1995.

[49] N. Nandwani, R. Caranza, and C. D. Hanning, "Obstructive sleep apnoea and upper airway reactivity," Journal of Sleep Research, vol. 7, no. 2, pp. 115-118, 1998.

[50] S. M. Garay, D. Rapoport, and B. Sorkin, "Regulation of ventilation in the obstructive sleep apnea syndrome," American Review of Respiratory Disease, vol. 124, no. 4, pp. 451-457, 1981.

[51] R. B. Berry, K. G. Kouchi, D. E. Der, M. J. Dickel, and R. W. Light, "Sleep apnea impairs the arousal response to airway occlusion," Chest, vol. 109, no. 6, pp. 1490-1496, 1996.

[52] D. J. Eckert, P. G. Catcheside, D. L. Stadler, R. McDonald, M. C. Hlavac, and R. D. McEvoy, "Acute sustained hypoxia suppresses the cough reflex in healthy subjects," American Journal of Respiratory and Critical Care Medicine, vol. 173, no. 5, pp. 506511, 2006

[53] D. J. Eckert, P. G. Catcheside, J. H. Smith, P. A. Frith, and R. Doug McEvoy, "Hypoxia suppresses symptom perception in asthma," American Journal of Respiratory and Critical Care Medicine, vol. 169, no. 11, pp. 1224-1230, 2004.

[54] A. M. Zanation and B. A. Senior, "The relationship between extraesophageal reflux (EER) and obstructive sleep apnea (OSA)," Sleep Medicine Reviews, vol. 9, no. 6, pp. 453-458, 2005.

[55] S. M. Harding, "Gastroesophageal reflux: a potential asthma trigger," Immunology and Allergy Clinics of North America, vol. 25, no. 1, pp. 131-148, 2005.

[56] D. A. Beuther, S. T. Weiss, and E. R. Sutherland, "Obesity and asthma," American Journal of Respiratory and Critical Care Medicine, vol. 174, no. 2, pp. 112-119, 2006.

[57] L.-P. Boulet, Q. Hamid, S. L. Bacon et al., "Symposium on obesity and asthma-november 2, 2006," Canadian Respiratory Journal, vol. 14, no. 4, pp. 201-208, 2007.

[58] J.-M. Kvamme, T. Wilsgaard, J. Florholmen, and B. K. Jacobsen, "Body mass index and disease burden in elderly men and women: the tromso study," European Journal of Epidemiology, vol. 25, no. 3, pp. 183-193, 2010.

[59] I. H. Van Veen, A. Ten Brinke, P. J. Sterk, K. F. Rabe, and E. $\mathrm{H}$. Bel, "Airway inflammation in obese and nonobese patients with difficult-to-treat asthma," Allergy, vol. 63, no. 5, pp. 570574, 2008. 
[60] K. J. Weatherwax, X. Lin, M. L. Marzec, and B. A. Malow, "Obstructive sleep apnea in epilepsy patients: the Sleep Apnea scale of the Sleep Disorders Questionnaire (SA-SDQ) is a useful screening instrument for obstructive sleep apnea in a diseasespecific population," Sleep Medicine, vol. 4, no. 6, pp. 517-521, 2003.

[61] L. H. Lancaster, W. R. Mason, J. A. Parnell et al., "Obstructive sleep apnea is common in idiopathic pulmonary fibrosis," Chest, vol. 136, no. 3, pp. 772-778, 2009.

[62] M. Knuiman, A. James, M. Divitini, and H. Bartholomew, "Longitudinal study of risk factors for habitual snoring in a general adult population: the Busselton Health Study," Chest, vol. 130, no. 6, pp. 1779-1783, 2006. 


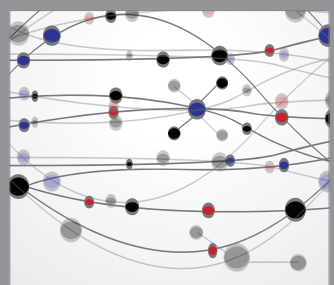

The Scientific World Journal
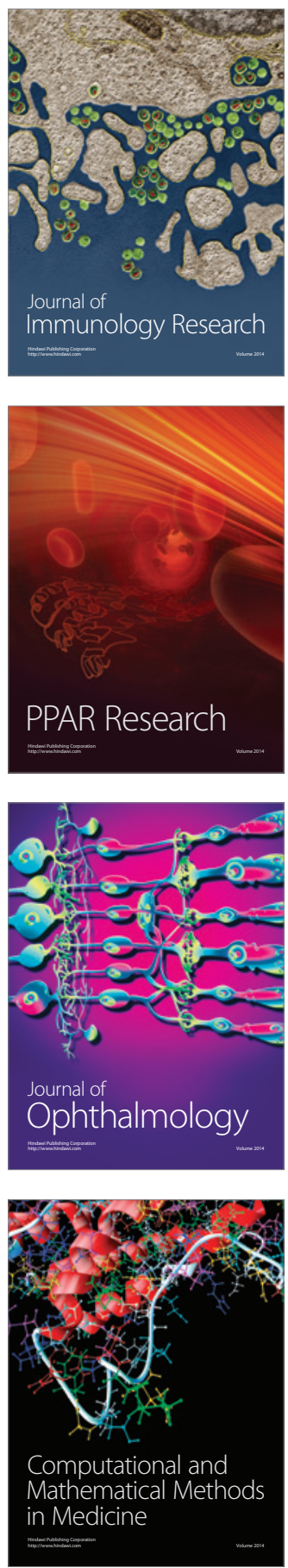

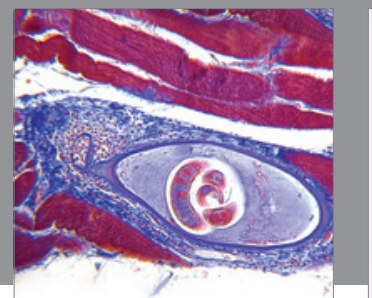

Gastroenterology

Research and Practice
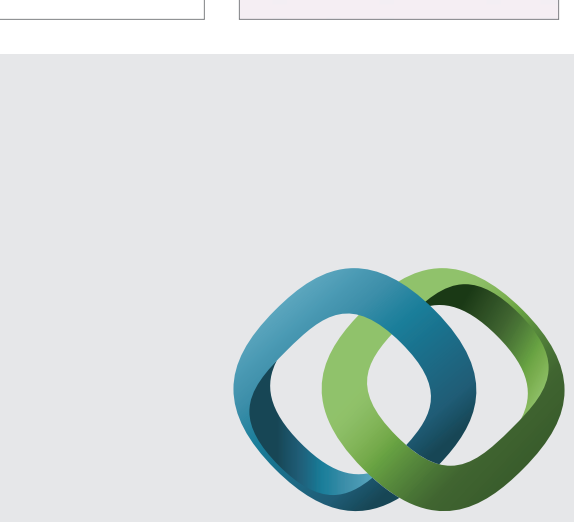

\section{Hindawi}

Submit your manuscripts at

http://www.hindawi.com
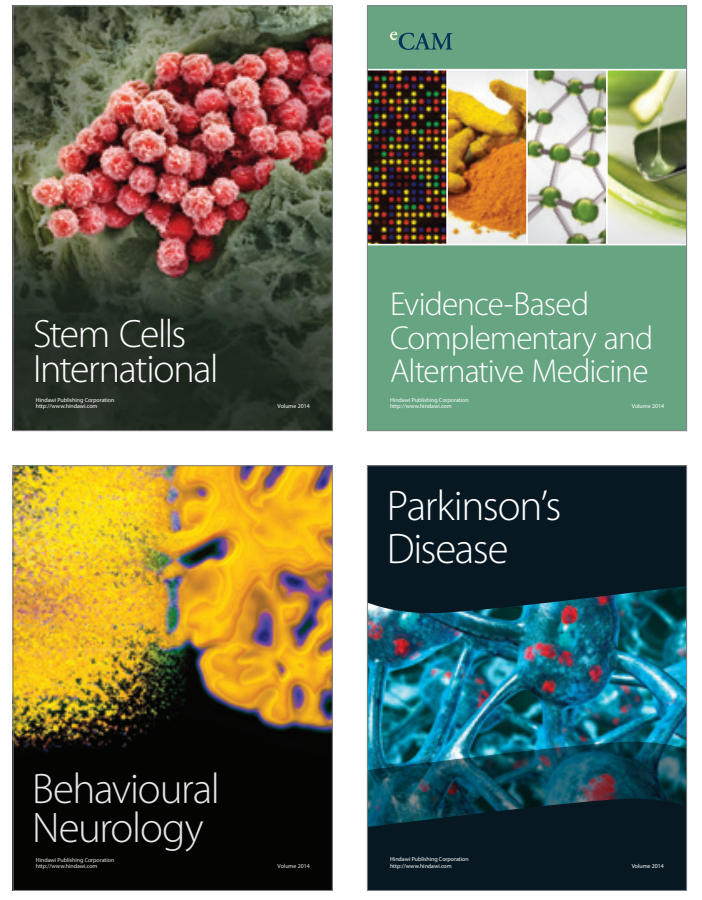
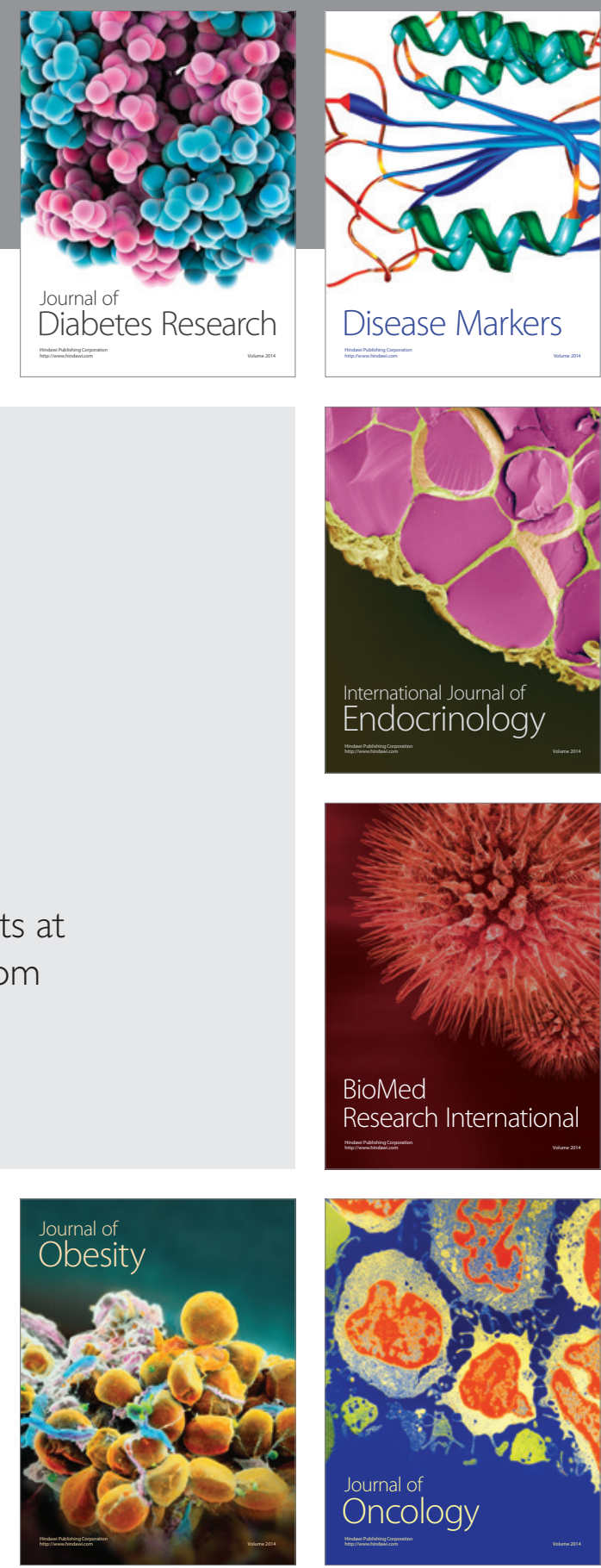

Disease Markers
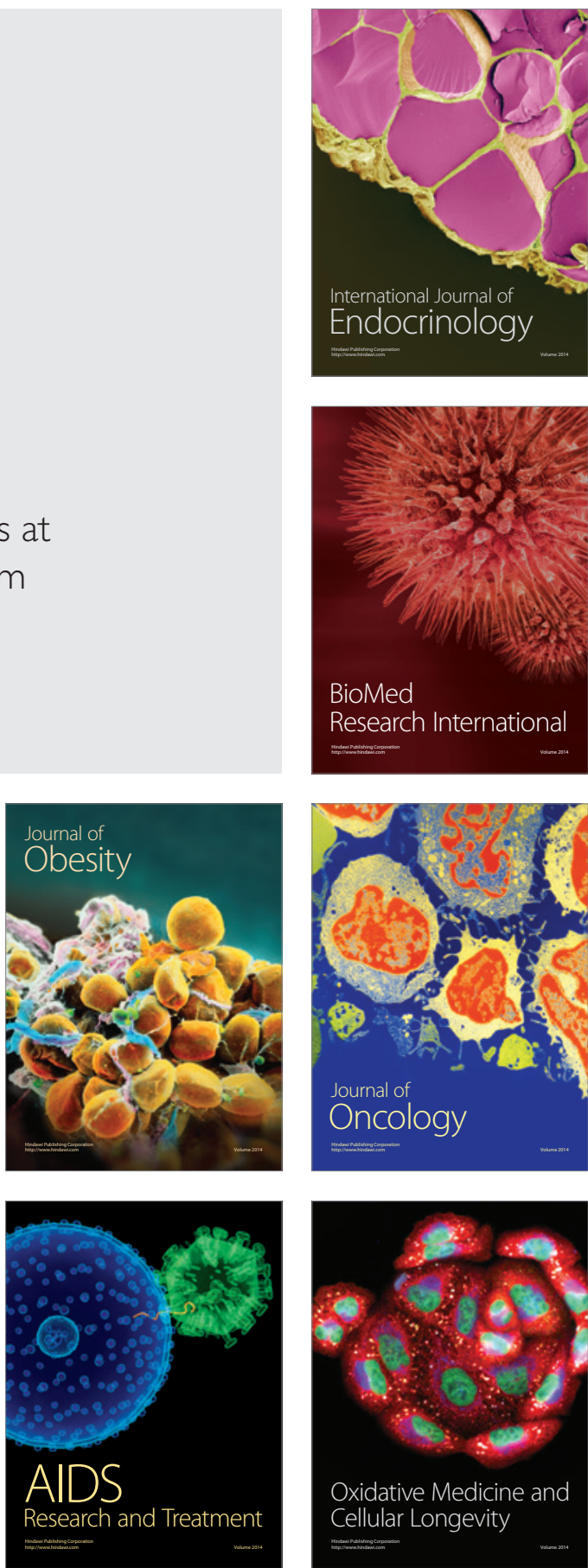